\title{
COMBINED EFFECT OF EGR AND ALUMINA WITH BIO-DIESEL BLEND ON THE OUTPUT OF CI ENGINE
}

\author{
G. JAMUNA RANI ${ }^{1}$, Y. V. HANUMANTHA RAO ${ }^{2} \&$ B. BALAKRISHNA ${ }^{3}$ \\ ${ }^{1}$ Assistant professor, Department of Mechanical Engineering, VRSEC, Vijayawada, Andhra Pradesh, India \\ ${ }^{2}$ Professor, Department of Mechanical Engineering, KLEF, Guntur, Andhra Pradesh, India \\ ${ }^{3}$ Professor, Department of Mechanical Engineering, University College of Engineering, JNTUK, Kakinada, India
}

\begin{abstract}
Exploratory examination was finished by utilizing Mahwa bio-diesel mix with the $\mathrm{Al}_{2} \mathrm{O} 3$ nano added substance and fumes gas distribution on the diesel motor to dissect the exhibition, ignition \&exhaust discharge qualities. The bio-diesel mix MBD25was arranged by including $25 \%$ Mahwa bio-fuel mixed with $75 \%$ of diesel fuel and MBD25AONP mix was set up by adding a 100 ppm of nano-particles (Alumina) to MBD25 fuel mix by volumetric premise. The perceptions shows that, there is an expansion of $5.52 \%$ brake warm productivity with the utilization of $\mathrm{Al}_{2} \mathrm{O}_{3}$ added substance with $\mathrm{MBD} 25$ mix, and 3.3\% expansion with alumina \& 20\% of EGR contrasted with the MBD25 mix. For the fuel mix MBD25AONP+20\% of EGR, Brake specific fuel consumption BSFC was diminished by $2.37 \%$ contrasted with MBD25 fuel mix. The NOx emanations development was decreased by $14.3 \%$ and outflows like $\mathrm{HC}, \mathrm{CO}$, and smoke were expanded by 10\%, $12.6 \%$, 9.1\% utilizing the fuel mix MBD25AONP+20\% of EGR contrasted with MBD25AONP fuel mix without EGR.

KEYWORDS: Mahwa Oil, Alumina, EGR, Additive, Emissions \& Performance
\end{abstract}

Received: Jun 06, 2020; Accepted: Jun 26, 2020; Published: Jun 30, 2020; Paper Id.: IJMPERDJUN2020174

\section{INTRODUCTION}

Humans life and the worldwide condition have been influenced by natural contamination brought about by the ignition of petroleum products. Because of the expanded populace and vehicle use, the current vitality request doesn't ready to meet by regular powers. Air contamination was made by the emanations tossed into the earth from the diesel motors. The bio-diesels are presented for decrease of outflows and decrease of an Earth-wide temperature boost, as the utilization of nano-particles as additives, improves the ignition of bio-diesel be accomplished and decrease of discharges. Creation and utilization of it's requirement for vitality and ecological concern. Compression Ignition motor could be run effectively utilizing distinctive bio-diesels like Mahwa, Rubber, tobacco \& Kharanja seed oils and so forth to get astounding execution and the emanations could be regulated. Experimentally explored on diesel motor with Mahwa bio-diesel mixes and inferred that the use of bio-diesel brings down the Particulate Matter (PM), Carbon dioxide $\left(\mathrm{CO}_{2}\right)$, UHC emissions and $\mathrm{CO}$ outflows and raised the fuel utilization and NOx emissions. The possibility of Mahwa seeds to deliver the bio-fuel utilizing pyrolosis strategy was verified and further portrayed the items genuinely \& Chemically. They uncovered that Mahwa seed bio-fuel is to be a Promising bio-fuel can be utilized as hydro-carbon fuel to get great results. The impact of affixing $10 \% \& 20 \%$ of Octanol in Mahwa oil was studied and found critical decrease in discharges. With the higher extent of the Octanol at full burden, $5.2 \%$ of $\mathrm{CO}$ discharges, $5.2 \%$ of $\mathrm{HC}$ emanations, $4.6 \%$ of NOx and $2.3 \%$ of smoke outflows decrease contrasted with flawless Mahwa oil bio-diesl. The impact of alumina $\left(\mathrm{Al}_{2} \mathrm{O}_{3}\right)$ \& Cerium oxide $\left(\mathrm{CeO}_{2}\right)$ particles expansion to the diesel was investigated and contrasted the outcomes and perfect diesel. They recognized a 
noteworthy reduction in NOx and CO discharges upto $13 \%$ \& $20.5 \%$. The outcomes demonstrated decrease in explicit fuel utilization and improvement in brake power. The impact of Cerium oxide $\left(\mathrm{CeO}_{2}\right)$ and Alumina nano-particles expansion to the Jathropa bio-diesel in various extents was investigated and watched the decrease in smoke outflows, Nitric oxide (NO), unburned. Hydrocarbons (UHC) and Carbon imonoxide (CO). Impact of the expansion of alumina particles to the Kharanja emulsified bio-diesel in various extents was verified. They investigated that, emulsified KBD fuel with Alumina particles improves. brake power and lessens the outflows contrasted with KBD emulsified fuel. 40ppm TiO2 particles was mixed with Calopyllum Inopyllum bio-diesel and tried on diesel motor. The $\mathrm{CO}$ emanations were diminished for the fuel and remaining discharges are increased. The increment in power at a pace of $1.0 \% \& 3.18 \%$ with the expansion of the $\mathrm{CuO}$ particles\& Al2O3 expansion of 50ppm to perfect diesel, SFC decreased by $0.6 \%$ \& $1.1 \%$ with $\mathrm{Al} 2 \mathrm{O} 3$ \& $\mathrm{CuO}$, outflows is decreased with the doping of nano particles. The mix of EGR \& Nano Emulsified Lemon Grass oil with an additive of DEE, lessens BSFC by $8.7 \%$, NOx emanations by $30.4 \%$, smoke emanations by $15.48 \%$, CO outflows by $2.33 \%$, and HC outflows by $21.3 \%$ than that of Lemon Grass bio-diesel mix utilized in DI diesel motor. Mahwa bio-diesel fuel mixes in various rates tried on a Kirloskar engine, TV1 model diesel motor \& MB25 mix was picked as the best mix for additional investigations to decrease NOx emanations. At full burden, Hot EGR gives most minimal explicit fuel utilization, iHydrocarbon outflows and better warmth discharge rate. The altered diesel motor with EGR and diminishing fuel injector spout gap measurement utilizing 20\% Mahwa bio-diesel mix as fuel was investigated. With their observations, suggested $10 \%$ halfway cooled iEGR for the proposed motor changes for better outcomes.

In this paper, the impact of alumina (A12O3) nano particles expansion to Mahwa bio-diesel (MBD25) mix with EGR on the discharges, burning and execution qualities of diesel motor is accounted for.

\section{EXPERIMENTAL SETUP}

The SEM image of Alumina nano-particles are shown in figure. 1. And the photographic image of Engine test rig is represented in figure 2. The tests were conducted on TV1 Kirloskar Type, CI engine and Exhaust emissions were observed by using gas analyser (Model AVL Digas 444N) and smoke meter (Model AVL, 437C).

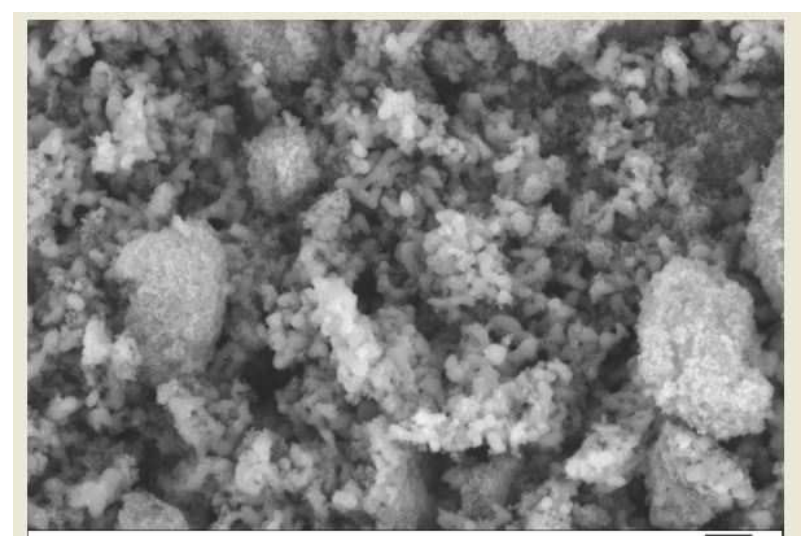

Figure 1: SEM Image of Alumina $\left(\mathrm{Al}_{2} \mathrm{O}_{3}\right)$ Nano-Particles. 


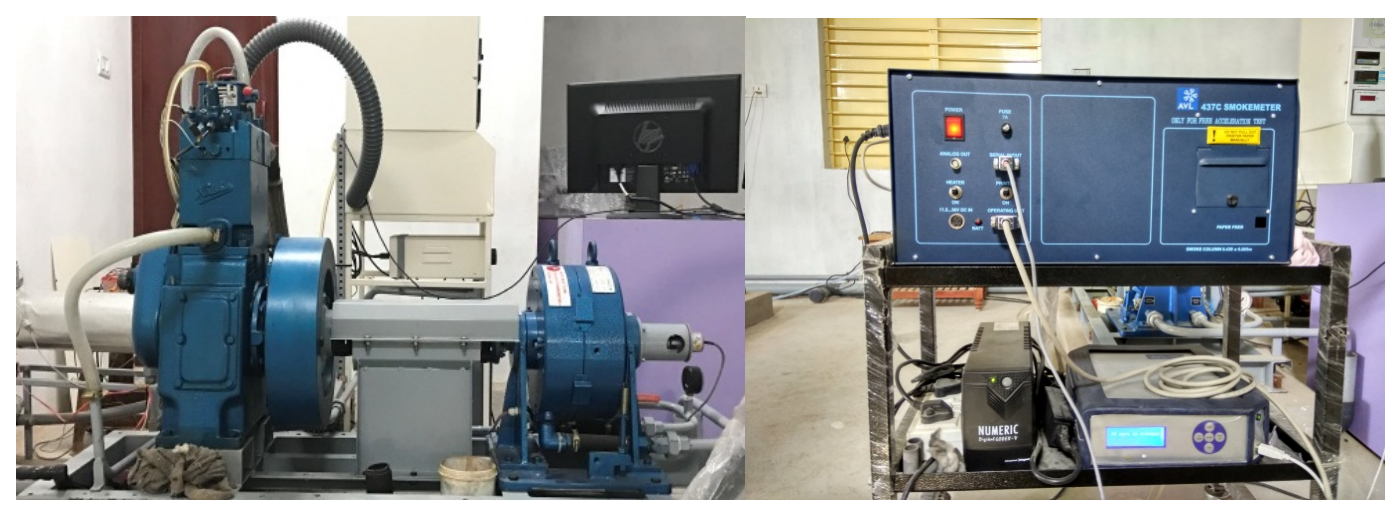

Figure 2: Engine Tested, Smoke Meter \& Exhaust Gas Analyzer.

The overall uncertainty of different parameters is calculated and is $\pm \mathrm{i} 2.18 \%$ by using the Square Root-.square Sum method, .shown below.

$$
\begin{aligned}
& =\mathrm{i} \text { Square rootof }\left\{(0.2)^{2}+(0.1)^{2}+(1.5)^{2}+.(0.3)^{2}+(0.1)^{2}+.(0.2)^{2}+.(1)^{2}+(1.1)^{2}+(0.2)^{2}\right\} \\
& =\mathrm{i} \pm 2.18 \%
\end{aligned}
$$

\section{METHOD OF EXHAUST IGAS RECIRCULATION, (EGR)}

EGR is the most broadly utilized strategy to diminish the arrangement of NOx outflows in diesel motor by recycling some division of fumes gases to bay complex. The stream pace of fumes gas distribution was constrained by utilizing a manometer linked to control valve at 0 to $10 \%$ of the EGR into the engine at the time of induction stroke. The level of EGR is characterized as the mass level of re-circled fumes gas in the complete admission blend.

\section{RESULTS \& DISCUSSIONS}

The performance, combustion \& emissions characteristics of 1-cylinder diesel engine was tested by using diesel, MBD25, MBD25AONP, MBD25+20\% of EGR, MBD25AONP+20\% of EGR fuels at varying loads and the results were discussed.

\subsection{Engine Performance}

\section{1. a. BTE}

Figure 3 represents the variations of BTE with the variation of load for the diesel, MBD25, MBD25AONP, MBD25+20\% of EGR and MBD25AONP+20\% of EGR. As the load on the engine increases, BTE of the engine increases to all the tested fuels. BTE of the MBD25 fuel is lower than the diesel fuel due to low heating value than the diesel fuel. 


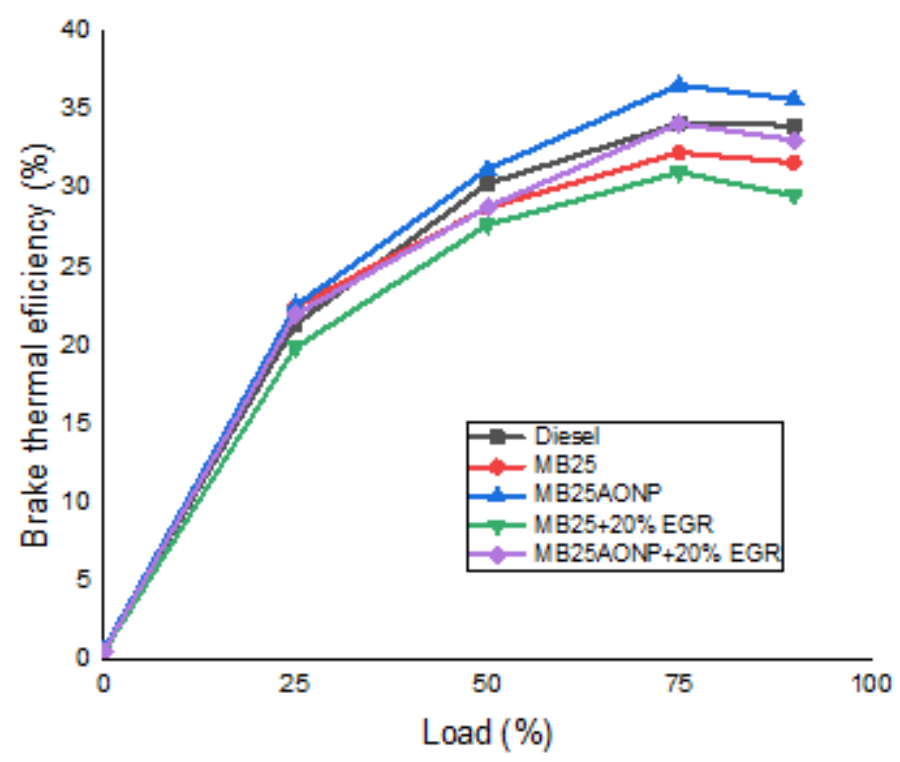

Figure 3: Variations in Brake Thermal Efficiency with Change in Load \%.

With the inclusion of nano-particles as additive to MBD25 fuel test, BTE is expanded than ithe diesel and MBD25 fuel. This is because of the expanded oxygen accessibility to the inclusion of Alumina particles with the bio-diesel mix. Brake thermal proficiency of MBD25 with $20 \%$ of EGR was diminished by $7.8 \%$ contrasted with the MBD25fuel test because of the lower oxygen content noticeable all around causes decrease in brake warm effectiveness. For MBS25AONP with $20 \%$ of EGR, fuel BTE is decreased by $7.2 \%$ and $2.6 \%$ than the MBD25AONP fuel and diesel sample fuel tests and expanded by $3.3 \%$ than MBD25 fuel sample.

\section{1.b. BSFC}

Figure 4 illustrates the variations in Brake specific .fuel Consumption (BSFC) with Change in load for the diesel fuel, MBD25 fuel, MBD25AONP fuel, MBD25 with 20\% of EGR and MBD25AONP with 20\% of EGR fuel sample. BSFC of the MBD25 fuel sample is increased by $4.5 \%$ in comparison to the diesel fuel due to low heating value and the higher viscosity. BSFC of the MBD25AONP fuel is reduced by $6.24 \%$ in comparison to that of MBD25 fuel. Mixing iof nano additive particles to bio-diesel blend, promotes combustion with the effect of catalytic reaction. For MBD25 fuel .blend with $20 \%$ of EGR mode, the BSFC is increased by $5.3 \%$ to that of MBD25 fuel blend. With the modification of EGR, less oxygen availability in the induced air causes to reduction in the combustion quantity of fuel. For the fuel sample MBD25AONP $+20 \%$ of EGR, the BSFC is raised by $4.2 \%$ \& $8.5 \%$ to that of MBD25AONP fuel \& diesel fuel .respectively at Max load condition. 


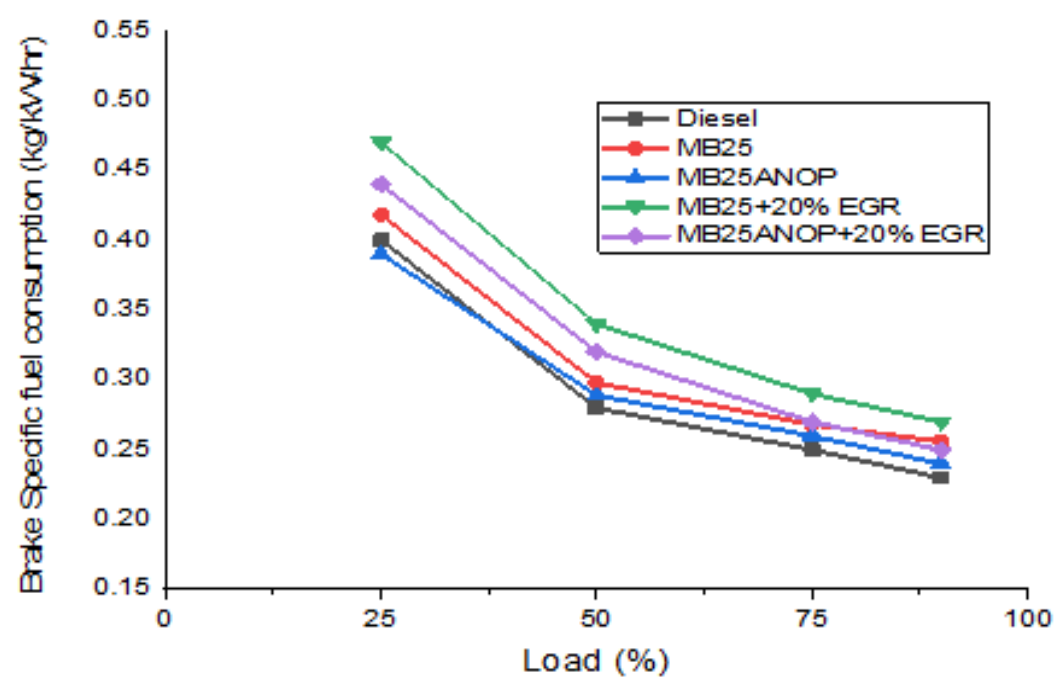

\subsection{Engine Emission Analysis}

Figure 4: Variations of Bsfc with Varying Load \%.

\section{2. a. CO in Exhaust Gases}

Figure 5 represents the Change in CO emissions with the varying loads for diesel, MBD25, MBD25AONP, MBD25 with $20 \%$ of EGR and MBD25AONP with $20 \%$ of EGR. Due ito the affluent oxygen icontent in MBD25 bio-diesel fuel CO emissions were lower than that of diesel Sample. With the insertion of alumina nano additive to the bio-diesel blend, the ignition delay diminishes and the icombustion process improves. By the addition of alumina particles to the MBD25 biodiesel blend, the $\mathrm{CO}$ emissions was diminished by $10.1 \%$ in comparison to MBD25 fuel sample. It is also identified that the $\mathrm{CO}$ emissions are raised by $13 \%$ with the cause of EGR imode for the MBD25 fuel. In addition to that, CO emissions were raised by $4 \%$ \& $11.2 \%$ for MBD25 fuel \& MBD25AONP fuel samples and decreases by $5.3 \%$ for the MBD25 with $20 \%$ of EGR fuel in comparison to the MBD25AONP with $20 \%$ of EGR fuel.

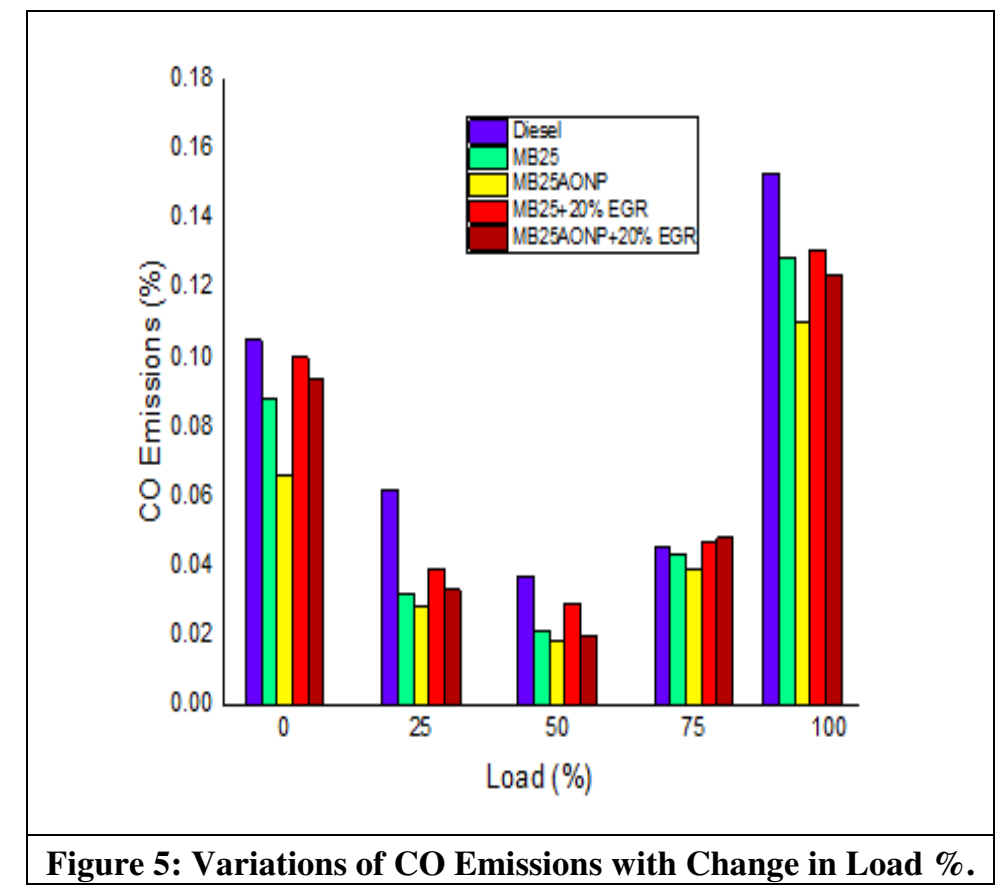




\section{2. b. HC in Exhaust Gases}

Figure 6 illustrates the changes in HC emissions with the change in load .With the cause of higher cetane number for the MBD25 bio-diesel blend leads to better combustion, It is noticed that the HC emission was lowered to that of diesel fuel. The UHC emissions was reduced by $9.3 \%$ with the doped alumina nano-particles to the MBD25 bio-diesel in comparison to the MBD25 bio-diesel fuel blend due to the less carbon molecules activated temperatures and enhances the combustion. With the use of EGR modification, the oxygen presence is less and caused poor combustion \& it leads to the formation of Hydro Carbon emissions. By the insertion of alumina particles as additives to the bio-diesel blend \& using EGR mode the HC Emissions are increased for MBD25 fuel sample, MBD25AONP, \& MBD25 + 20\% EGR fuel samples.

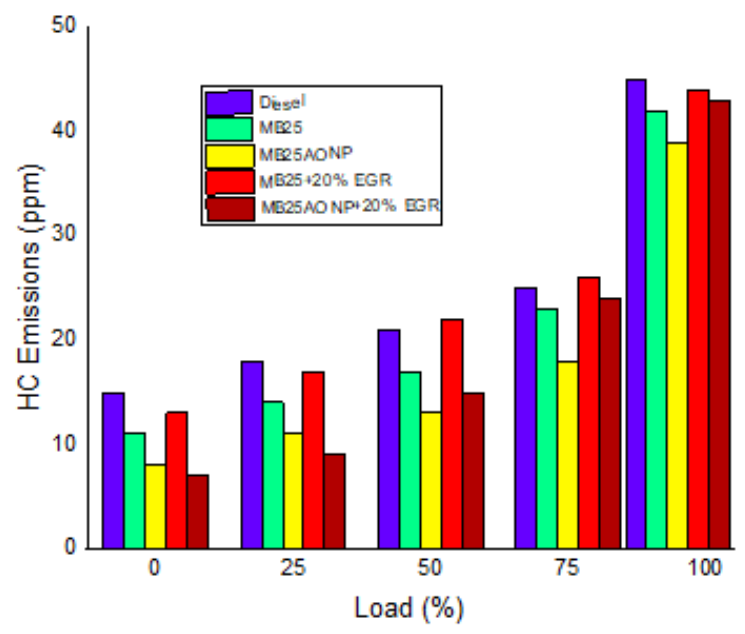

Figure 6: Variations of the HC Emissions by Changing in Load \%.

\section{2. c. NOx}

Figure 7 exhibits the variations in NOx emissions by varying loads for diesel fuel, MBD25 fuel, MBD25ANP fuel, MBD25 with 20\% EGR, MBD25AONP with $20 \%$ of EGR. The iNOx emissions by using all the tested fuels were increased with a rise in the load because of improvement in the Combustion temperature at Maximum loads conditions.

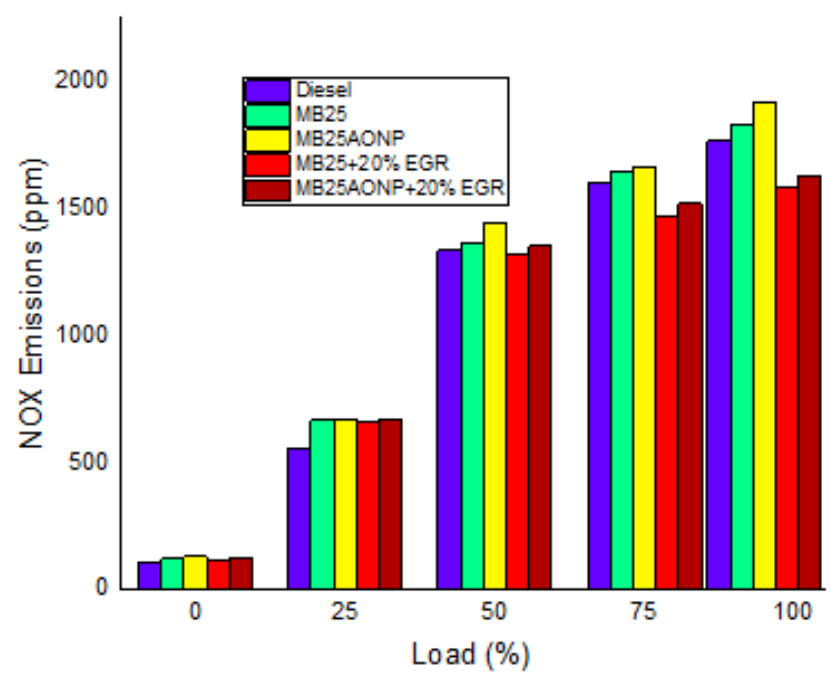

Figure 7: Variations of NOx Emission with Varying Load \%. 
It is observed that the development of the NOx emissions for the MBD25 bio-diesel blend is greater than the Diesel fuel sample due to the high flame temperature. The insertion of alumina particles to MBD25 fuel NOx Emissions were raised by $4.5 \%$ bio-diesel than the MBD25 fuel because of added catalytic reaction by the nano-particles additive. The NOx emission was increased by $12.5 \%$ by the use of EGR to the MBD25 fuel compared to that of MBD25 fuel.

\subsubsection{Smoke Opacity}

Figure 8 illustrates the ivariations in Smoke opacity with changing in load. For MBD25 fuel sample the smoke opacity was less than the diesel fuel due to the more availability of oxygen contents in bio-diesel and results in enhanced combustion. The smoke emissions were reduced by $5.1 \%$ with the blending of Alumina particles to MBD25 fuel in comparison to the MBD25 fuel. The shorter delay in the first phase of combustion and the prominent air- fuel mixing with the association of nano-particles leads to improved combustion and it causes reduced smoke opacity. Smoke emissions are raised by $4.2 \%$ with the use of EGR mode to the MBD25 fuel in comparison to the MBD25 fuel without the modification of engine with EGRi. For MBD25AONP fuel with $20 \%$ of EGR, the Smoke emissions iwere increased by $2.7 \%, 7.5 \%$ \& $9.1 \%$ in comparison to the MBD25 fuel, MBD25 with 20\% EGR, and MBD25AONP fuel, respectively.

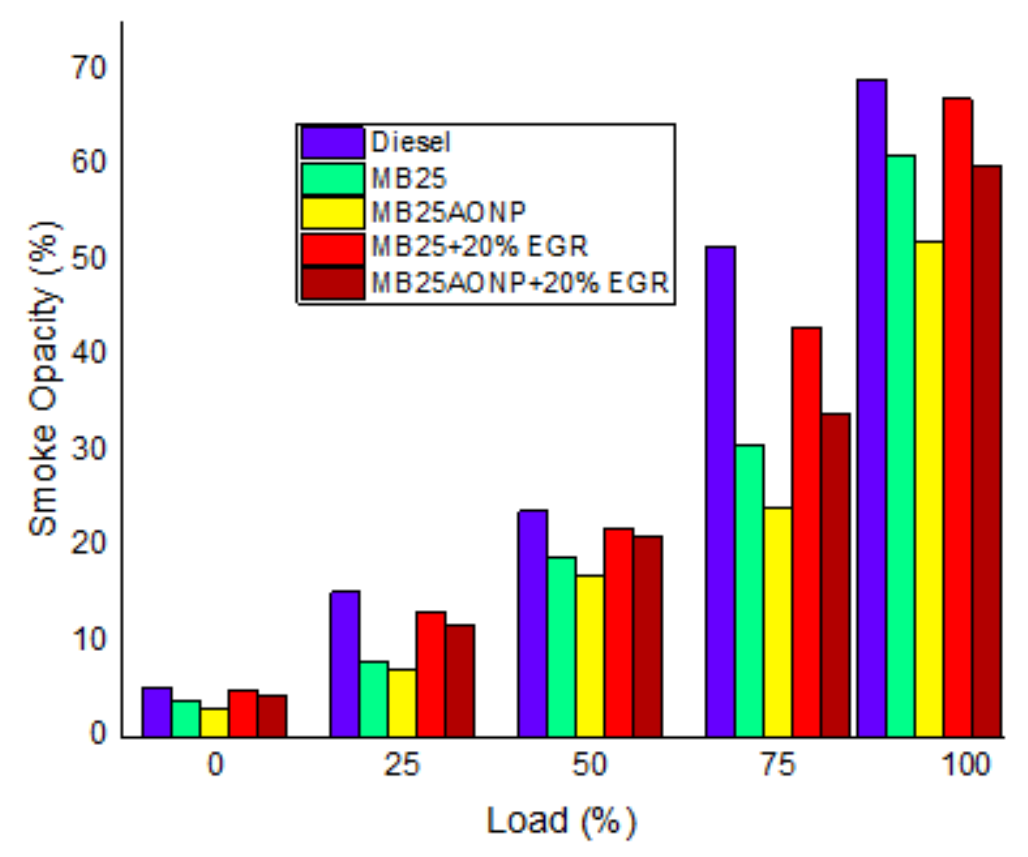

Figure 8: Variations of Brake Thermal Efficiency(BTE) with Varying Load \%.

\section{CONCLUSIONS}

The results obtained with the experimentation on a diesel engine using different fuel samples and the EGR modification are listed below:

- $\quad$ BTE for the fuel MBD25AONP is raised by $5.3 \%$ and $7.5 \%$ icompared to the MBD25 andMBD25AONP + 20\% of EGR fuels, respectively. The BSFC of MBD25AONP fuel decreases by $6.25 \%$ and increased by $4.1 \%$ .compared to the MBD25 fuel and MBD25AONP with 20\% of EGR.

- $\mathrm{CO}$ emissions for the engine were decreased for the MBD25AONP sample by $6.5 \%$ in comparison to the MBD25 
fuel sample\& the HC emissions also decreased, compared to that of MBD25 fuel usage.

- NOx emissions from the engine were downed by $7.36 \%$ for the fuel sample MBD25AONP to that of MBD25 fuel. .For fuel MBD25AONP +EGR., the NOx emissions were 8.9\% downed in comparison to the MBD25 fuel.

- Smoke opacity emissions iwere reduced for the MBD25AONP fuel by $6.5 \%$ to that of MB2D5 fuel. And for the fuel MBD25AONP with the use .of EGR smoke was increased by $2.7 \%$ to that of MBD25 fuel.

\section{REFERENCES}

1. Agarwal, Deepak, Shrawan Kumar Singh, and Avinash Kumar Agarwal. "Effect of Exhaust Gas Recirculation (EGR) on performance, emissions, deposits and durability of a constant speed compression ignition engine. "Applied energy 88, no. 8 (2011): 2900-2907.

2. Ashraful, A. Masjuki, Hassan H. Masjuki, Md A. Kalam, IM Rizwanul Fattah, S. Imtenan, S. A. Shahir, and H. M. Mobarak. "Production and comparison of fuel properties, engine performance, and emission characteristics of bio-diesel from various non-edible vegetable oils: A review." Energy Conversion and Management 80 (2014): 202-228.

3. Bhaskar, K., G. Nagarajan, and S. Sampath. "The performance and emission characteristics of fish oil methyl esters (fome) and diesel blends in a partially premixed charge compression ignition engine." International journal of green energy 11, no. 4 (2014): 389-403.

4. De Serio, Domenico, Alex de Oliveira, and José Ricardo Sodré. "Effects of EGR rate on performance and emissions of a diesel power generator fueled by B7." Journal of the Brazilian Society of Mechanical Sciences and Engineering 39, no. 6 (2017): 1919-1927.

5. Gumus, S., Ozcan, H., Ozbey, M., Topaloglu, B., "Aluminum oxide and copper oxide nanodiesel fuel properties and usage in a compression ignition engine ”, Fuel, (2016), PP.163, 80-87.

6. Karthikeyan, S., Elango, A., \& Prathima, A., "The effect of cerium oxide additive on the performance and emission characteristics of a CI engine operated with rice bran bio-diesel and its blends", International Journal of Green Energy, 13(3), (2016), PP.267-273.

7. Kumar, M. V., Babu, A. V., Kumar, P. R., \& Reddy, S. S. "Experimental investigation of the combustion characteristics of Mahwa oil bio-diesel-diesel blend using a DI diesel engine modified with EGR and nozzle hole orifice diameter", Bio-fuel Res. J, 5(3), (2018), PP.863-871.

8. Mahalingam, A., Devarajan, Y., Radhakrishnan, S., Vellaiyan, S., \& Nagappan, B., "Emissions analysis on Mahwa oil biodiesel and higher alcohol blends in diesel engine”, Alexandria Engineering Journal, 57(4), (2018), PP.2627-2631.

9. Panwar, N. L., Shrirame, H. Y., Rathore, N. S., Jindal, S., \& Kurchania, A. K. (2010). Performance evaluation of a diesel engine fueled with methyl ester of castor seed oil. Applied Thermal Engineering, 30(2-3), 245-249.

10. Prabu, A., \& Anand, R. B., "Emission control strategy by adding alumina and cerium oxide nano particle in biodiesel”, Journal of the Energy Institute, 89(3), (2016), PP.366-372.

11. Prabhu, B. Dinesh, A. Ramesh, and J. Venkatesh. "Experimental Investigation and Analysis of Mechanical Properties of Polyvinyl Ester/Glass Fiber Composite with Alumina (Al2o3), Molybdenum Disulfide (Mos2) And Titanium Oxide (Tio2) Fillers." International Journal of Mechanical and Production Engineering Research and Development (IJMPERD) 8. 6, Dec 2018, 125-134 
12. Pradhan, D., Singh, R. K., Bendu, H., \& Mund, R., "Pyrolysis of Mahwa seed (Madhuca indica)-Production of bio-fuel and its characterization”, Energy conversion and management, 108, (2016), PP.529-538.

13. Prasad, G. V. L., \& Gupta, A. V. S. S. K. S., "Role of nano additive blended karanja bio-diesel emulsion fuel on performance and emission characteristics of diesel engine (No. 2016-28-0165). SAE Technical Paper (2016).

14. Rajan, K., \& Senthilkumar, K. R., "Effect of exhaust gas recirculation (EGR) on the performance and emission characteristics of diesel engine with sunflower oil methyl ester”, JJMIE, 3(4), (2009), PP.306-311.

15. Saber, D., Kh Abd El-Aziz, and A. Fathy. "Corrosion behavior of copper-alumina nanocomposites in different corrosive media." Int. J. Mech. Eng 5 (2016): 1-10.

16. Sakhare, N. M., Shelke, P. S., \& Lahane, S., "Experimental investigation of effect of exhaust gas recirculation and cottonseed B20 bio-diesel fuel on diesel engine”, Procedia Technology, 25, (2016), PP.869-876.

17. Sanjay, K. C., Shreyas, P. V., Gafoor, S. S. A., Biju, T., \& Raju, K., "Effect of alumina nano-particles on the performance and emission characteristics of CI engine fuelled with lard oil methyl ester blends", American Journal of Materials Science, 6(4A), (2016), PP.94-98.

18. Saraee, H. S., Jafarmadar, S., Taghavifar, H., \& Ashrafi, S. J., "Reduction of emissions and fuel consumption in a compression ignition engine using nano-particles”, International journal of environmental science and technology, 12(7), (2015), PP.2245-2252.

19. Saritha, P., et al. "Mechanical Characterization and Wear Behaviour of Al7075 Alloy Reinforced with Alumina And Molybdenum Disulphide." International Journal of Mechanical and Production Engineering Research and Development (IJMPERD) 8. 6, Dec 2018, 395-404

20. Sathiyamoorthi, R., \&Sankaranarayanan, G. (2015)."Fuel injection timings of a direct injection diesel engine running on neat lemongrass oil-diesel blends”, International Journal of Automotive and Mechanical Engineering, 11, 2348.

21. Shaafi, T., \& Velraj, R. (2015). "Influence of alumina nano-particles, ethanol and isopropanol blend as additive with dieselsoybean bio-diesel blend fuel: Combustion, engine performance and emissions", Renewable Energy, 80, 655-663.

22. Solaimuthu, C., Ganesan, V., Senthilkumar, D., \& Ramasamy, K. K. (2015). "Emission reductions studies of a bio-diesel engine using EGR and SCR for agriculture operations in developing countries. ” Applied energy, 138, 91-98.

23. Naik, R. T., and C. Nilesh. "Emission characteristic of a high speed diesel engine." International Journal of Mechanical Engineering, 5, 2936 (2016).

\section{AUTHORS PROFILE}

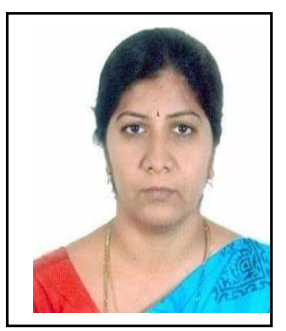

Mrs.G. Jamuna Rani, Asst. Professor in the Dept. of ME, VRSEC has twelve years of teaching experience and have publications around 15 in international journals and confrences. Her area of interest in reserch are Alternate fules and IC engines. 


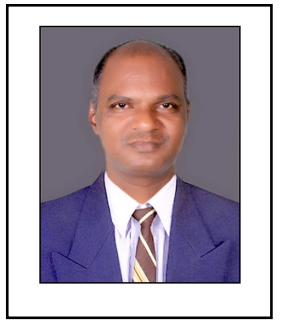

Dr.YV.Hanumatha Rao, Professor in the Dept. of ME, KLEF, Andhra pradesh. He is having around 25 years of research, acedmic \& administration experience. He has publications of technical papers, around 40 research publications in various journals with good impact factor. He is interested in research in the areas of Alternate Fuels, Refrigeration \& Heat Engines.

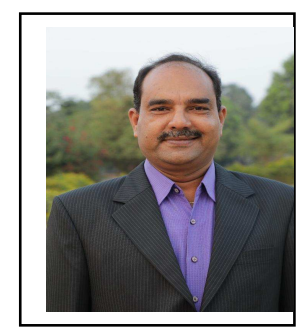

Dr B. Balakrishna, Principal, university college of Engineering, JNTUK, Kakinada. He has publications more than 36 papers in the international journals with good impact factor and citations. He have around 25 years of academic, administrative and reserch experience. He is interested in research in the areas of Alternate fuels, Heat Engines \& Fluid dynamics. 